\title{
Инновационная технология содержания кур-несушек на сетчатых полах
}

\begin{abstract}
Кавтарашвили А.Ш., доктор сельскохозяйственных наук, профессор, Заслуженный деятель науки РФ, главный научный сотрудник - зав. лабораторией технологии производства яиц

ФГБНУ Федеральный научный центр «Всероссийский научно-исследовательский и технологический институт птицеводства» Российской академии наук (ФНЦ «ВНИТИП» РАН)
\end{abstract}

Аннотащия: Прибодится абторская классисикация систем содержания кур-несушек. Дана краткая характеристика различных систем (клеточной, различных вариантов напольной, быгульной), их достоинств и недостаткоб. Подробно рассмотрена иннобационная технология содержания кур-несушек на сетчатых полах, характеризующаяся бысоким уровнем абтоматизации технологических процессов, 6 том числе яйцесбора и пометоудаления.

Ключебые слоба: куры-несушки, системы содержания, сетчатые полы, яйцесбор, пометоудаление.

Введение. Активизация с начала 80-х гг. прошлого века протестных движений ученых, различных общественных организаций и политических партий по защите животных привела с 1999 г. к законодательной (Директива 1999/74/ ЕC) поэтапной отмене использования в странах ЕС традиционных клеточных батарей для производства яиц и мяса птицы, и процесс этот был завершен в 2012 г. Этому способствовал также растущий спрос потребителя на птицеводческую продукцию, произведенную с использованием высоких стандартов благополучия птицы.

Исторически благополучие животных определялось отсутствием негативных переживаний, таких как болезни, голод, жажда, стресс или снижение физической кондиции. В настоящее время хорошее благосостояние животных предполагает сочетание адекватного питания, соответствующих условий окружающей среды, оптимального здоровья, возможности проявления естественных видов поведения, и позитивного психического состояния.
Считается, что реализация естественных или врожденных форм поведения является компонентом биологического функционирования организма, доставляет удовольствие животному и необходимо для того, чтобы избежать стресса.

У кур-несушек врожденное поведение включает в себя купание в пыли, сидение на насесте, поиск корма и поведение, связанное со снесением яйца. Эти формы поведения часто обусловлены внутренними факторами и подвержены физиологическому регулированию.

Характеристика различных систем содержания кур. Вышеуказанные виды поведения во многом зависят от системы содержания кур-несушек. Все системы содержания птицы условно можно разделить на клеточные и неклеточные. В клеточные системы входят традиционные и оснащенные (меблированные) клетки, которые бывают одно- и многоярусные. K неклеточным (альтернативным) системам относят системы содержания на глубокой подстилке (полностью), на сетчатых полах (планчатых, металлических или пластиковых) и в вольерах (одно-, двух- $n$ трехуровневых). В последних двух системах не менее $1 / 3$ птичника должна быть покрыта глубокой подстилкой. Неклеточные системы могут быть с выгулами (ограниченный или свободный выгул, покрытый травой - органические системы) и без выгулов.

Основными недостатками замкнутых традиционных клеточных батарей является то, что птицы не могут распрямлять крылья и махать ими, свободно двигаться, не касаясь друг друга, или стоять в полный рост в задней части клетки. Они не могут пользоваться насестом, летать, подтачивать когти, прихорашиваться, купаться в пыли, в полной мере проявлять поведение, связанное с поиском корма и снесением яйца (из-за отсутствия гнезда). Снижение подвижности птицы приводит к жировой дистрофии печени, остеопорозу и повышенному риску переломов ног и крыльев во время отлова птицы. С другой стороны, 
традиционные клеточные батареи имеют ряд преимуществ. Птицы не имеют контактов со своими экскрементами, что снижает риск заражения различными болезнями, лучше сохраняется качество воздуха, чистота снесенных яиц и оперения. Ограничение движения и отсутствие насестов снижает риск деформации и переломов килевой кости. Кроме того, небольшое поголовье кур в клетке со стабильным иерархическим порядком также снижает риск расклева пера и каннибализма.

Оснащенные или меблированные клетки сохраняют многие преимущества традиционных клеток без недостатка строгих поведенческих ограничений. Однако в меблированных клетках, уступающих традиционным клеткам по санитарно-гигиеническим условиям, выше смертность птицы, повреждение и загрязнение яиц. Основным преимуществом меблированных клеток по сравнению с большинством неклеточных систем является лучшая гигиена, что приводит к сравнительно низкому риску заражения паразитами или инфекционными агентами и, следовательно, К снижению отхода поголовья. Основной минус меблированных клеток - отсутствие пылевых ванн и возможности поиска корма, а использование насеста курами в течение значительного времени дня (40-50\%) может привести к искривлению и повреждению килевой кости. В целом, недостатки оснащенных клеток зависят от конкретных конструктивных особенностей системы, генотипа птицы и величины сообщества.

В неклеточных (альтернативных) системах содержания птицы имеют более широкие возможности для проявления пол- ного поведенческого репертуара, особенно в системах свободного выгула. Прочность костей птицы увеличивается из-за повышенной свободы движения, возможности летать и махать крыльями. Наличие гнезд в таких системах нормализует поведение кур, связанное со снесением яиц. Повышенная доступность пространства позволяет слабым курам избегать контактов с агрессивными особями. Основными недостатками неклеточных систем являются повышенный риск расклева пера и каннибализма и, следовательно, увеличения (до 37\%) отхода поголовья по причине падежа и выбраковки. Некоторые из этих систем также показывают высокий процент переломов костей (до 50\%), возникающих в результате столкновения птицы при полете с насестами, гнездовыми и другими конструкциями. Подчиненные по иерархии особи могут иметь ограниченный доступ к воде и корму. При содержании птицы на глубокой подстилке риск заболеваний (особенно кокцидиоза) значительно возрастает в связи с контактом с влажным пометом, повышением уровня загрязнения воздуха, приводящим к более высокой инфекционной нагрузке и ослаблению иммунной системы кур-несушек. В системах свободного выгула аналогичные риски возникают также из-за контакта с дикими птицами, а также существует более высокий риск хищничества.

Концентрация газообразного аммиака обычно высока в вольерах, напольных и сетчатых системaх, в которых помет не удаляется регулярно, тогда как в меблированных клетках она обычно ниже.

Следует отметить, что организация неклеточных (альтернативных) систем содержания птицы требует больших площадей, сложна в обслуживании, требует значительных энергозатрат и оставляет немало вопросов относительно здоровья и сохранности стада.

Инновационная технология содержания кур-несушек на сетчатых полах. В связи с вышеизложенным отечественный производитель клеточного и напольного оборудования для содержания птицы поставил перед собой сложную, и на первый взгляд, амбициозную задачу - разработать такую технологию содержания кур-несушек, которая удовлетворяла бы всех: общественность (гуманное отношение $\mathrm{K}$ птице), производителя (экономическая эффективность производства), потребителя (производство экологически чистой продукции с использованием высоких стандартов благополучия птицы), птицу (комфортность и возможность выполнения врожденных форм поведения). Для решения этой задачи в 2017 г. был создан инновационный центр, который на основании анализа состояния птицеводческой отрасли, изучения тенденций развития мирового птицеводства, результатов обширных научных исследований, знаний и опыта специалистов-технологов в кратчайшие сроки разработал, научно обосновал и реализовал технологию содержания кур-несушек «EGGoist» (рис. 1). В новой технологии разработчики применили преимущества клеточной и альтернативных систем, максимально учли требования общественных организаций, потребителя и сертифицирующих структур к условиям содержания птицы, предоставив ей все необходимые свободы, а также интересы производителя по защите инвестиций и обеспечения эффективности производства. 


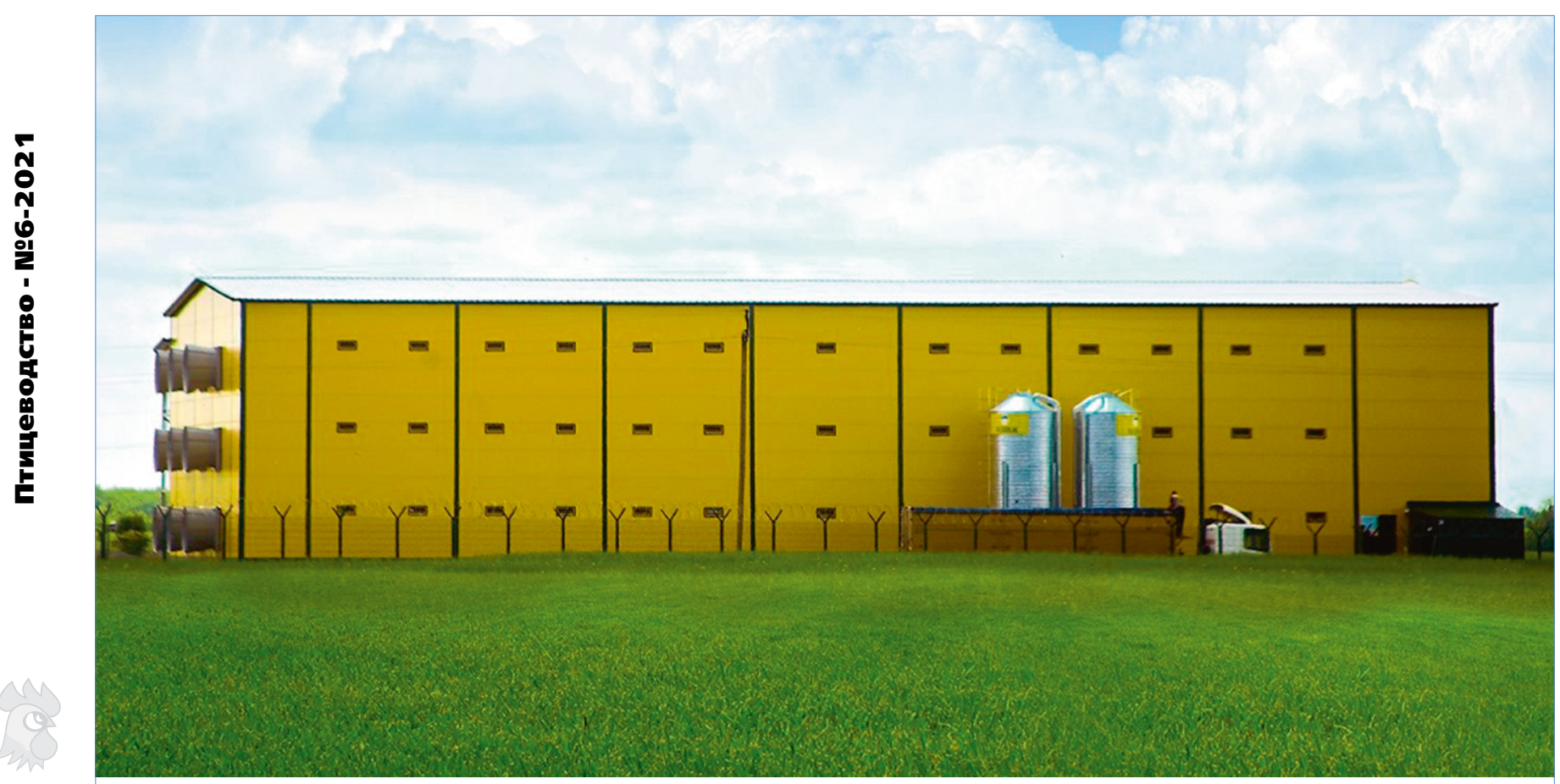

Рисунок 1. Трехуровневый птичник с технологией «EGGoist»

Привлекательность новой технологии содержания кур-несушек, в первую очередь, обусловлена тем, что вместо строительства трех птичников для напольного содержания несушек строится один вместимостью, равной трем, и следовательно, снижаются затраты на строительство зданий, внутренние и наружные коммуникации, приобретение земельных площадей и оборудования. Значительно сокращается потребность в дорогостоящем и часто дефицитном подстилочном материале. Автоматизация всех технологических процессов, легкость обращения с оборудованием, качественный микроклимат, простота управления и безопасность эксплуатации такого птичника создают хорошие условия труда и, следовательно, облегчает наем обслуживающего персонала. А главное - это гарантия того, что такое птицеводческое предприятие без труда примет вызовы будущего. Ведь создаваемые в нем условия и способ организации производства на шаг впереди существующих требований к современному птичнику. Как бы ни изменились стандарты, такой объект можно с легкостью привести в соответствие любым нормам и директивам с помощью небольших трансформаций.

Новая технология предполагает строительство многоуровневого птичника с интеграцией оборудования в здание. Возведение корпуса и монтаж производственных систем происходят одновременно. По мере наращивания каркаса здания устанавливаются решетчатые полы, линии кормления, поения, автоматические гнезда, системы яйцесбора и пометоудаления, элементы микроклимата, освещение и автоматика. По завершении этапа строительства птичник полностью готов к эксплуатации. Выгода такого комплексного подхода очевидна, он позволяет сэкономить средства, время и трудовые ресурсы.

Благодаря гибкости и простоте конструкций и организации пространства птичника технология допускает внесение не только незначительных изменений, но и открыта для серьезных конструктивных вмешательств. Способствуют перевоплощениям и широкие возможности системы автоматики, которые позволяют регулировать и контролировать работу производственных систем на каждом этаже отдельно.

Технология предполагает выполнение требований сертифицирующих органов к бесклеточному содержанию птицы и обеспечивает условия содержания курнесушек, прописанные Директивами ЕС (рис. 2). На каждом этаже многоуровневого птичника 15\% полезной площади пола отведено под так называемое «загребание» и «пылевые ванны»; элементы оборудования, с которыми соприкасается птица, моются и дезинфицируются по технологической необходимости; уборка помета производится ежедневно.

Система подачи корма полностью автоматизирована. Достав- 
ка кормов из внешних бункеров хранения осуществляется с помощью шнековых транспортеров или транспортеров цепь-шайба. Продольное кормление осуществляется цепной кормораздачей, которая обеспечивает дозированное равномерное распределение корма вдоль всех линий на всех этажах.

Узел водоподготовки состоит из фильтра, водомера, медикатора, запорных клапанов и манометра. Каждая линия поения оснащена регулятором давления, ниппельными поилками вертикального действия $и$ каплеулавливателями. Линии поения выполнены в сборе с насестами, что обеспечивает им дополнительную жесткость. Полипропиленовые трубы квадратного сечения укомплектовываются ниппельными поилками в заводских условиях, благодаря чему достигается высокое качество и герметичность линий. Длина применяемых труб - 6 м, что позволяет сократить количество соединений. Высоту линий поения можно регулировать вручную или с помощью мотора-редуктора, это дает возможность беспрепятстенно следовать технологии содержания кур-несушек, а также осуществлять мойку и дезинфекцию оборудования.

Одна из важнейших особенностей новой технологии - автоматизированный яйцесбор (рис. 3). Сбор яиц производится автоматически вдоль птичника. Лента яйцесбора, изготовленная из перфорированного полипропилена шириной 500 мм, доставляет яйца на элеватор птичника, приемный стол или прямо на поперечный транспортер. Блок управления яйцесбором позволяет дать старт работам как вручную, так и по

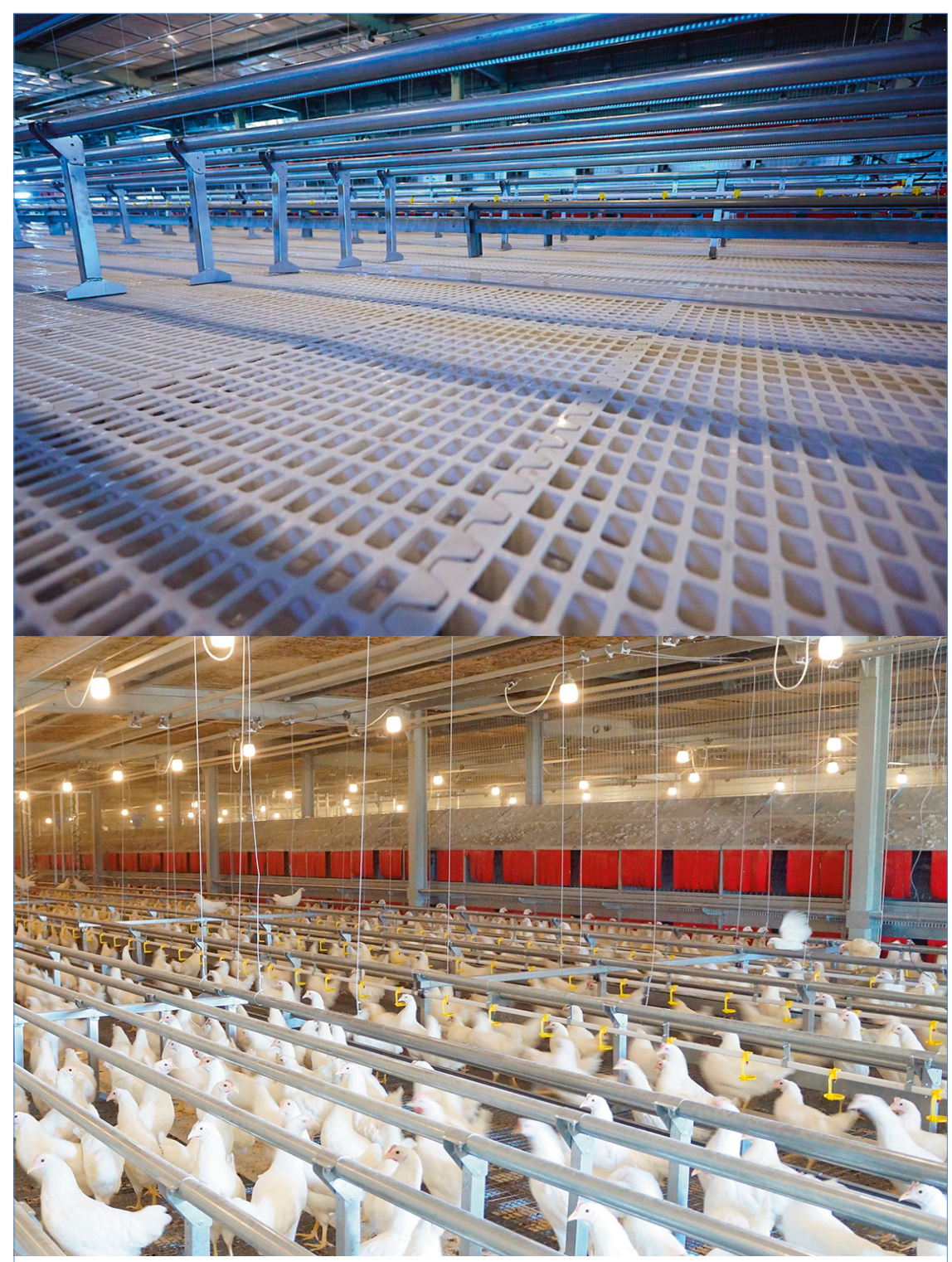

Рисунок 2. Вид птичника изнутри

сигналу из центральной комнаты яйцесбора птицефермы.

Автоматические гнезда могут располагаться по центру или по бокам параллельно линиям кормления и поения на каждом этаже. Допускается применение одно-, двух- и трехэтажных гнезд в зависимости от ширины здания. Количество гнезд зависит от поголовья, из расчета 1 гнездо на 65 несушек. Параметры гнезда: ширина 1200 мм, глубина 454 мм, наклон решетки пола $7^{0}$. Покрытие поликов гнезд - Astroturf (искусственная трава) - имитирует естественные условия, что благопри- ятно сказывается на яйценоскости кур, и, вместе с тем, обеспечивает и сохранность яйца, благодаря плавному скатыванию на ленту яйцесбора. Конструкция гнезда предохраняет снесенные яйца от загрязнения пометом и расклевывания их несушками. Для предотвращения нахождения кур в гнездах в ночное время предусмотрены решетчатые выталкиватели. Приводимые в движение электроприводом, они вынуждают птицу покинуть гнезда.

Автоматизированное пометоудаление - еще одно определяющее преимущество новой техно- 
логии (рис. 4). Возможность ежедневной уборки помета из птичника значительно улучшает его гигиену и благоприятно отражается на состоянии здоровья птицы. Благодаря наличию решетчатых полов сокращается контакт птицы с пометом, что снижает риск возникновения дерматитов груди и ног и заражения птицы гельминтами. А низкое содержание аммиака в воздухе уменьшает риск заболеваний дыхательных путей. Помет собирается с помощью полипропиленовой ленты, проходящей под решетками полов каждого ряда. Поперечные транспортеры выводят помет с каждого этажа здания, а наклонный конвейер птичника доставляет его на транспортное средство или в место хранения и переработки в удобрение. Каждый продольный транспортер приводится в движение отдельным моторомредуктором. Запуск системы производится с диммеров вручную или автоматически, попеременно или одновременно.

Свойства применяемой полипропиленовой ленты способствуют длительной эксплуатации. Лента устойчива к кислотам, щелочам, большинству органических растворителей и повышенным температурам; предел прочности на растяжение до 3,0 т на 1 см²; благодаря низкой адгезии поверхность ленты легко очищается.

Необходимую интенсивность и равномерность освещения на уровне птицы обеспечивают потолочные светодиодные светильники. Плавное включение («рассвет») и выключение («закат») света с необходимой продолжительностью дает возможность курам усаживаться на ночлег без волнений и травм. Освещение регулируется автоматически с помо-

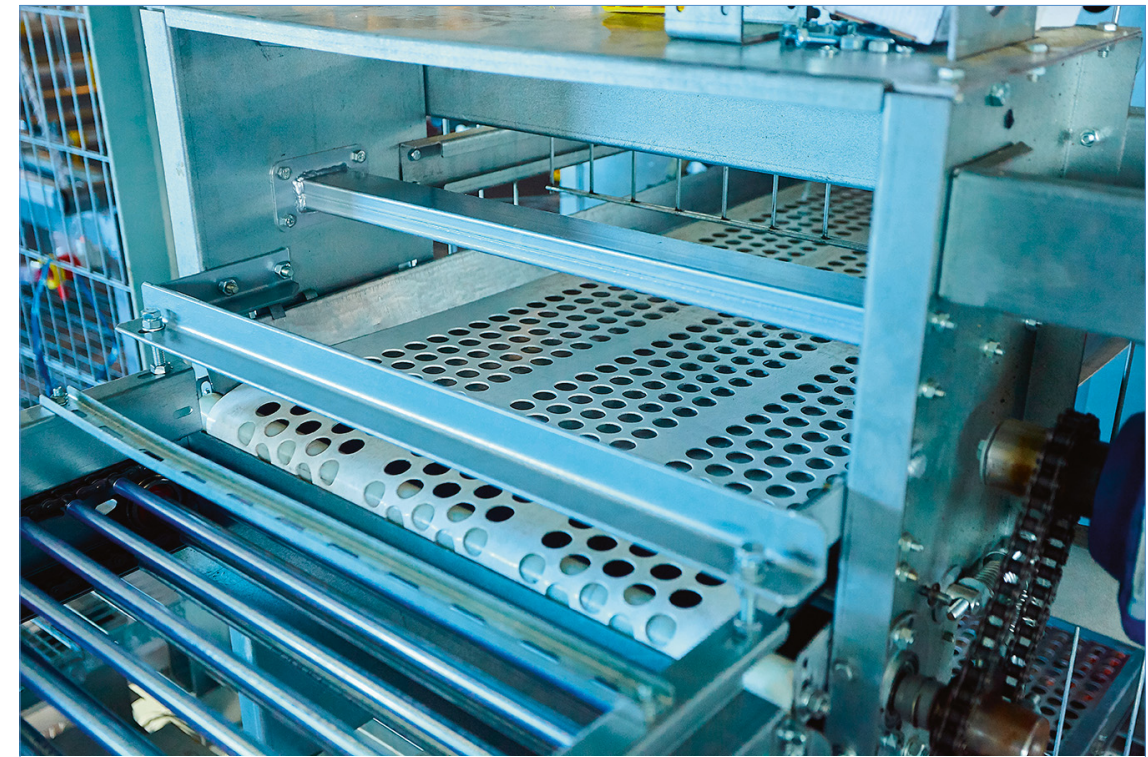

Рисунок 3. Автоматизированный яйцесбор

щью блока управления, осуществляющего включение и выключение света, регулирование интенсивности освещения и имитацию «восхода» и «заката» солнца по заданной программе за весь срок содержания птицы.

Оборудование для создания микроклимата обеспечивает необходимые параметры и условия для здоровой жизни и высокой продуктивности птицы. Регулировка вентиляции осуществляется с помощью климатического компьютера, который контролирует объем воздуха, проходяще-

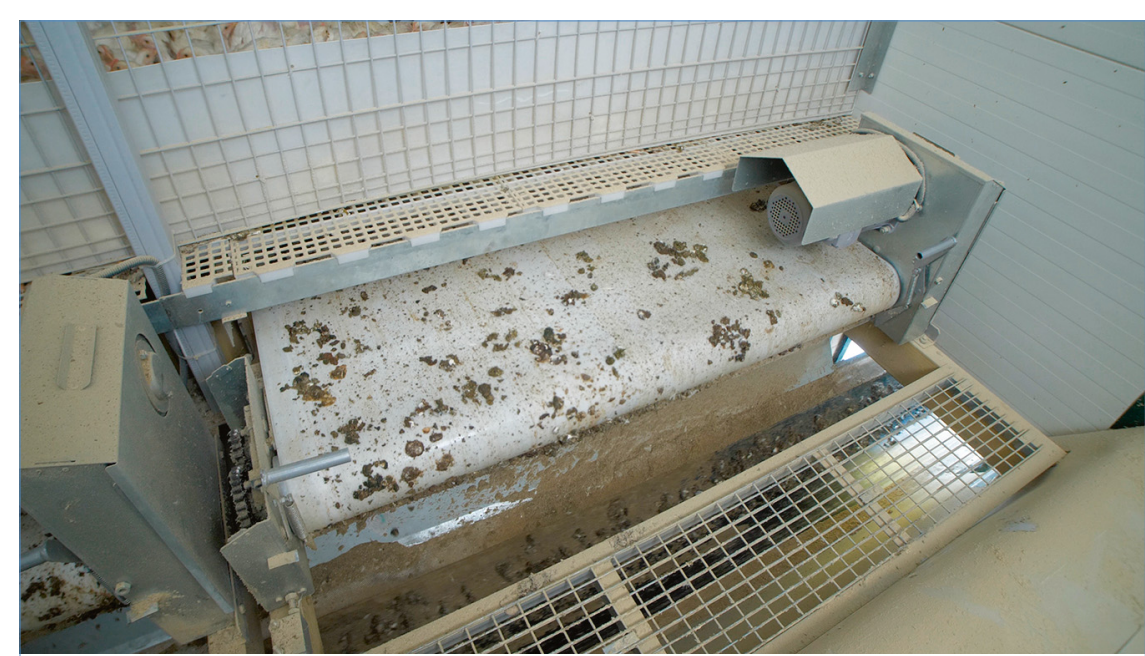

Рисунок 4. Автоматизированное пометоудаление го через воздухозаборники, и скорость вращения туннельных вентиляторов в зависимости от температуры и содержания $\mathrm{CO}_{2}$. Параметры воздуха внутри птичника оцениваются по критериям температуры, влажности и давления. Во всем птичнике поддерживаются одинаковые условия содержания птицы благодаря синхронизации компьютеров на разных этажах. Минимальный режим вентиляции предполагает обеспечение притока воздуха через приточные клапаны в боковых стенах, управляемые мото-

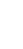


рами, и оттока воздуха при помощи вентиляторов с переменной скоростью на задней стене. При летнем, туннельном, режиме вентиляции приток воздуха осуществляется через торцевые клапаны с контролируемой скоростью или через панели увлажнения при их наличии. Для обогрева птичника можно использовать тепловентиляторы и/или лучевые инфракрасные нагреватели.

Технология EGGoist предполагает полную автоматизацию систем яйцесбора, взвешивания кормов, подачи воды и кормов, пометоудаления и создания микроклимата.

С момента установки оборудования системы работают в соответствии с необходимыми режимами без участия человека. В случае внештатной ситуации или возникновения необходимости настройки или обслуживания той или иной системы можно воспользоваться аварийной кнопкой выключения.

Система автоматического яйцесбора позволяет управлять процессом сбора яиц согласно установкам таймера без вовлечения обслуживающего персонала. Управление элеватором и продольными лентами яйцесбора осуществляется по отдельности. Система допускает возмож- ность регулировки скорости сбора яиц по необходимости.

Система автоматической кормораздачи обеспечивает управление процессом раздачи кормов без участия человека в соответствии с установками таймеров. В программе задаются параметры времени и продолжительности кормления, а также количество циклов. Система обеспечивает взвешивание кормов для каждого уровня птичника.

Автоматика системы пометоудаления предусматривает все необходимые технологические блокировки. Управление и регулировку системы производит оператор в соответствии с требованиями технологов птицефабрики: осуществляет включение/выключение необходимых лент продольного пометоудаления, поперечных и наклонного транспортеров выгрузки помета из птичника.

Таймеры в контроллерах микроклимата программируются таким образом, чтобы остановить производственные системы в случае необходимости проведения операции по сбору яйца или уборке, мойке, настройке систем или узлов.

Данные всех систем собираются и анализируются с помощью специального программного обе- спечения, реализуя, таким образом, потребность в диспетчеризации процессов в птичнике.

В составе каждой системы есть звуковая и световая сигнализация, а также аварийное оповещение.

Результаты испытания новой технологии при содержании кур промышленного стада кросса Хай-Лайн показали, что новая технология при максимальном соблюдении условий благополучия птицы, современных требований общественных организаций, потребителя и сертифицирующих структур ЕС к ее содержанию обеспечивает высокую сохранность поголовья и реализацию генетического потенциала продуктивности кур-несушек современных высокопродуктивных кроссов.

Заключение. Таким образом, инновационная технология содержания кур на сетчатых полах включает все достоинства клеточной и напольной систем, и ее внедрение позволит производить инкубационные и пищевые яйца кур яичных и мясных кроссов с использованием высоких стандартов благополучия поголовья.

\section{Для контакта с автором:}

\section{Кавтарашвили Алексей \\ Шамилович}

E-mail: alexk@vnitip.ru

\title{
The Innovative Management System for Layers with Slatted Floor
}

\author{
Kavtarashvili A.Sh. \\ Federal Scientific Center "All-Russian Research and Technological Institute of Poultry" \\ of Russian Academy of Sciences \\ Summary: The classification of the systems of layers' management developed by the author is presented; all \\ systems (including systems with cage housing, floor housing, free range systems) are briefly characterized and \\ their shortages and advantages are presented. The innovative management system for layers with slatted floor \\ is detailed; this system is highly automated including the important processes of egg collection and elimination
} of manure.

Keywords: layers, management systems, slatted floor, egg collection, elimination of manure. 